\title{
O ESTADO ENTRE O LIBERALISMO E O NEOLIBERALISMO
}

ROCHA, Manoel Ilson Cordeiro ${ }^{1}$

\begin{abstract}
RESUMO: O neoliberalismo não é apenas o resgate dos princípios do Estado mínimo e da liberdade de mercado; diferencia-se pelos seus atores e pelas condições contemporâneas do poder. É preciso contextualizar estes atores e estas condições para defini-lo e compará-lo com o liberalismo clássico. Esta definição implica em identificar a orientação do capital internacional para o Estado, restringindo a sua intervenção na economia e reduzindo as barreiras nacionais ao trânsito de mercadorias e capitais. Sob o título de globalização, se reúnem os fenômenos de internacionalização da economia e, sob o título de neoliberalismo, as reformas do Estado em seus ordenamentos jurídicos, para atender à economia globalizada.
\end{abstract}

PALAVRAS-CHAVE: Estado. Neoliberalismo. Globalização.

SUMMARY: Neoliberalism is not only the rescue of the principles of the minimum State and of the market freedom, it differentiates for its actors and the contemporaries conditions of the power. She is necessary to contextualize these actors and these conditions defin it and compares it with classic liberalism. This definition implies in identifying the orientation of the international capital the State, restricting its intervention in economy and reducing the national barriers to the transit of merchandises and capitals. Under the globalization heading, it congregates the phenomena of internationalization of economy and under the heading of neoliberalism, the reforms of the State in its legal systems, to deal the global economy.

KEYWORDS: State. Neoliberalism. Globalization.

\section{ESTADO E CAPITALISMO}

A formatação do Estado, com base no princípio da soberania, a partir de Maquiavel e caracterizado como Estado Moderno, não tem uma legitimação uniforme do poder. A gradativa maturação do capitalismo alterou a condição de seus atores, e, na imbricada relação entre a estrutura de poder político e a organização dos meios de produção, os argumentos suficientes à estabilização das relações sociais, em especial para a interferência na composição do poder público, renovaram-se, acompanhando o status dos atores econômicos.

Uma divisão cíclica permite sobrepor, no tempo, os argumentos de legitimação. Mas o Estado a que se refere o tema é o de orientação liberal clássica, que se estende da sua Revolução até o início do século passado, quando passou a vigorar o intervencionismo estatal sob o título de Estado do bem estar. No Estado liberal, a idéia de liberdade individual como condição para a legitimidade do Estado, fundada no contratualismo de John Locke, propiciou a aplicação das leis de mercado de Adam Smith e a redução a um Estado mínimo controlador da paz social e protetor dos princípios do sistema. No outro lado está o Estado neoliberal, marcado pelas reformas na máquina pública social democrata, a partir da década de 70 do século XX até os

1 Mestre em Direito Público e Professor de Direito. E-mail: manoelilson@uol.com.br 
dias de hoje. O caráter destas reformas é, também, a redução da máquina a um Estado mínimo, regulador da economia e ausente nas demandas de serviços públicos construídas na socialdemocracia. Mas o fundamento não é o mesmo do liberalismo clássico; aqui, há o envolvimento dos governados no ambiente de mercado global e na necessidade de controlar gastos públicos, para acompanhar a competitividade desse mercado. O Estado mínimo, numa sociedade com o padrão de consumo, com o volume de riqueza, com o nível de tecnologia e com a explosão demográfica do século XXI, não pode ser equiparado ao Estado mínimo do século XIX. O Estado, agora, já é uma máquina imensurável e o movimento neoliberal a reduziu relativamente. O próprio fundamento do Estado se perdeu na complexa burocracia e o poder se legitima, para uns, em si próprio, como um meio, e, para outros, em concepções vagas como o bem comum. Em ambos os períodos, prevaleceram o constitucionalismo, o equilíbrio de poderes e o princípio formal da soberania.

Mas o Estado do liberalismo ao neoliberalismo, em seu fundamento, é um só: capitalista explicado pelo racionalismo iluminista. A acumulação primitiva do capital combinada com o colonialismo europeu garantiu as condições adequadas ao sistema moderno de produção, com o uso da razão e do empirismo para explorar os recursos infindáveis da natureza e reinventá-la como sua, num movimento de superação contínua que caracteriza a modernidade em sua essência, não apenas como "o que é atual", mas como o "estar se atualizando ininterruptamente". Para regular as tensões, que neste modelo são essenciais, estabeleceu-se um modelo de organização do poder, fundado em limites rígidos dos territórios, com fronteiras definidas por tratados e uma relação de poder que faz da fronteira o limite entre a exclusividade interna de governo e o reconhecimento externo recíproco da soberania numa comunidade de Estados. A eficiência do sistema capitalista garantiu a sua expansão por todo o mundo, ressalvadas as peculiaridades e níveis de desenvolvimento de cada sociedade, e, também, as sociedades políticas foram reproduzindo, dentro de determinados limites locais, o padrão de organização institucional, como num movimento "natural" de vinculação ou somatória das ações de condicionamento da vontade humana nas esferas política e econômica. Reproduziu-se o modelo ocidental a partir das sociedades capitalistas européias, de forma a se tornar hegemônico entre as sociedades políticas contemporâneas.

\section{AS NOVAS CONDIÇÕES DO PODER E A GLOBALIZAÇÃo}

Vive-se um momento em que a dialética da modernidade assume contornos mais evidentes. Uma série de fenômenos interligados já pode ser precisada e identificada como pertencente a um único movimento: um aparente movimento de integração das sociedades em alguns aspectos e, em outros, um movimento de ruptura - um dialético movimento de ruptura e integração simultaneamente.

Esse movimento é denominado, genericamente, de "globalização". Mas não é um 
movimento metodicamente identificado. Sua noção é tão fluida que não convém, neste momento, precisar o termo para além da compreensão de que seja um movimento de reestruturação contemporânea da sociedade. Porém, no conjunto de fenômenos sociais globalizantes há diversas manifestações de poder, notadamente econômicas, que podem ser caracterizadas como ação da classe detentora do poder econômico para ampliar o processo de acumulação - eixo da lógica capitalista. Por isso, o interesse especial em analisar especificamente o que se chama de "globalização econômica".

É possível entender esses fenômenos por partes. A globalização econômica é a internacionalização da distribuição do processo de acumulação global do capital que leva à criação de um mercado tendente à planetarização. A maximização da acumulação do capital leva ao desenvolvimento das forças produtivas e das relações de produção e de comércio à escala mundial.

Já na esfera de poder ideológico-cultural, seguindo a dinâmica da constante superação desencadeada pela modernidade, há também uma "acumulação" de experiências culturais por agentes culturais ávidos por novos espaços que se clareiam diante da alternativa global aberta pelos agentes econômicos - já que o movimento das esferas de poder, em muito, se confundem. Com a globalização cultural, vêem-se, no meio social, por um lado, instrumentos ideológicos legitimadores, do tipo dos identificados por diversos autores como "pós-modernos", com seus agentes de mídia global, de redes informacionais globais, responsáveis pela homogeneização cultural e pela venda de novas fórmulas de racionalização e de ideais de consumo, e, por outro lado, o processo excludente do movimento, por repelir todos os que a ele não se adaptam - e para tanto basta não fazer parte do processo produtivo, o que culmina num ambiente social heterogêneo composto de excluídos da globalização e de incluídos nela.

Como desdobramento, a esfera política passa por uma onda de "turbulência" na busca de adaptação a essa nova ordem, por um lado; e de sobrevivência das antigas estruturas, por outro. Como, por exemplo, na América Latina, ajustes estabilizadores e reformas estruturais são continuamente implementados na tentativa de se adaptar à nova ordem mundial, ou como o estabelecimento de fronteiras novas na Europa, diante das pressões internas dos nacionalismos e das pressões externas do capital internacional.

A globalização reúne fenômenos diversos que devem ser compreendidos em conjunto, úteis em maior ou menor grau à internacionalização do capital. Foram enumerados, segundo Ianni (1992), em síntese e exemplificativos: 1. mundialização da economia, mediante a internacionalização dos mercados, rompendo com as fronteiras geográficas clássicas; 2. desconcentração do aparelho estatal, mediante a descentralização de suas obrigações, a "desformalização" de suas responsabilidades, a privatização de empresas públicas e a 'deslegalização' da legislação social; 3. internacionalização do Estado com os blocos regionais e os tratados de livre comércio; 4. desterritorialização e reorganização do espaço da produção mediante a superação do modelo fordista pelo toyotista; 5. fragmentação das atividades produtivas, que permite aos conglomerados multinacionais praticar o comércio inter-empresa 
e possibilita o direcionamento dos investimentos para países de legislação mais favorável; 6 . expansão de um Direito paralelo ao dos Estados, de natureza internacional; 7. estabelecimento de uma rede de comunicação mundial, onde INTERNET, telejornalismo, turismo, transporte aéreo, telefonia via satélite, etc., internacionalizam o inglês dentro de outra série de símbolos que viabilizam todas essas relações globais, com um processo paralelo de integração e homogeneização.

Movimentos de globalização da sociedade não é nenhuma novidade. Mas, se o termo pode ser identificado com outras manifestações do gênero, ao longo da história da humanidade, que fique claro que se trata, aqui, de um conceito histórico: a onda globalizante contemporânea, neoliberal, virtual, "pós-moderna”, etc.

\section{REESTRUTURAÇÃO CONTEMPORÂNEA DO ESTADO}

O Estado, como sociedade política fundada em fronteiras e limites que asseguram uma distribuição político-jurídica de um poder organizado, mesmo formal ou de autonomia limitada, serviu bem ao sistema produtivo contemporâneo, apesar das diferentes naturezas de expansão de ambos, já que este último nunca se dispôs a conhecer fronteiras.

Na história moderna, as reais fronteiras dominantes da economia-mundo capitalista expandiram-se intensamente desde as suas origens no século XVI, de tal maneira que hoje elas cobrem toda a terra... Uma economia-mundo é constituída por uma rede de processos produtivos, interligados, que podemos denominar 'cadeias de mercadorias', de tal forma que, para qualquer processo de produção na cadeia, há certo número de vínculos para adiante e para trás, dos quais o processo em causa e as pessoas nele envolvidas dependem... Nesta cadeia de mercadorias, articulada por laços que se cruzam, a produção está baseada no princípio da maximização da acumulação do capital (WALLERSTEIN apud IANNI, 1992, p. 32).

Entretanto, a economia capitalista articulou-se dentro dos limites do Estado. Como afirma Ianni (1992), funcionou, até então, numa "economia-mundo", mas não num "Estadomundo". Karl Marx constatou o internacionalismo do capitalismo há quase dois séculos; os modelos de organização política e social assumiram os contornos territoriais conhecidos. Não há um contra-senso na distribuição do poder na sociedade moderna, pelo caráter de expansão de cada esfera, porque as classes econômicas detentoras do capital, que, reivindicaram o poder nesse período, sempre se beneficiaram das estruturas políticas, uma vez que, dada a inicial expansão global do capital, não havia se estabelecido a contraposição entre relações de poder global e relações de poder territorial.

A natureza internacionalista do capitalismo, pela expansão de mercados, viabilizou a sua dinâmica natural de centralização e concentração do capital, pressuposto da sua sobrevivência. 
o capitalismo tanto revoluciona as outras formas de organização social e técnica do trabalho e da produção com as quais entra em contato, como transforma reiteradamente as formas de organização social e técnica do trabalho e da produção já existentes em moldes capitalistas (IANNI, 1992, p 141/142).

O fim do século XX reflete tanto essa versatilidade do modelo de produção como a confirmação do conflito entre as esferas de poder econômico e político no estabelecimento do padrão das relações, no que toca ao seu nível de concentração - a generalização das políticas de desestatização, desregulação, privatização, abertura de mercados, maior fluxo das forças produtivas, modernização das normas político-jurídicas e das instituições que organizam as relações de produção. Esta é a resposta - elaborada conforme avaliação interna das melhores condições para o capitalismo e posta em prática em consórcio com os governos das sociedades políticas - às novas condições de produção, como o alcance mundial da acumulação do capital financeiro e industrial, a terceira revolução industrial e a própria "vitória" na disputa "hegemônica" pelo poder com a esfera política.

A perda, para a esmagadora maioria dos países capitalistas, de boa parte de sua capacidade de conduzir um desenvolvimento parcialmente autocentrado e independente; o desaparecimento de certa especificidade dos mercados nacionais e a destruição, para muitos Estados, da possibilidade de levar adiante políticas próprias, não são conseqüência mecânica da globalização, intervindo como processo "externo". (...). Sem a intervenção política ativa dos governos Thatcher e Reagan, e também do conjunto de governos que aceitaram não resistir a eles, e sem a implementação de políticas de desregulamentação, de privatização e de liberação do comércio, o capital financeiro internacional e os grandes grupos multinacionais não teriam podido destruir tão depressa e tão radicalmente os entraves e freios à liberdade deles de se expandirem à vontade (CHESNAIS, 1996, p. 34).

Deve-se, porém, ter consciência de que o poder econômico não pretende extinguir o poder político, mas adequar a sua estrutura ao âmbito de determinação internacional. As medidas de caráter institucional citadas devem ser somadas a toda uma construção ideológica de legitimidade para definir o cenário político do Estado contemporâneo - modelo de estrutura para a sociedade política que o capital internacional formulou para uma sociedade globalizada.

O neoliberalismo político se caracteriza pela série de reformas legais redutoras do Estado que marcaram as décadas de 80 e 90 em muitos países e que, em maior ou menor medida, continuam. Para resumir as reformas necessárias ao modelo, os principais interlocutores do capital se reuniram e elaboraram uma "cartilha" denominada Consenso de Washington com os seguintes itens: 1. disciplina fiscal para eliminação do déficit público; 2. mudança das prioridades em relação às despesas públicas, com a superação de subsídios; 3. reforma tributária, mediante a universalização dos contribuintes e o aumento dos impostos; 4. adoção de taxas de juros positiva; 5 . determinação da taxa de câmbio pelo mercado; 6. liberalização do comércio exterior; 7. extinção de restrições para os investimentos diretos; 8. privatização das empresas 
públicas; 9. desregulação das atividades produtivas e 10. Ampliação da segurança patrimonial, por meio do fortalecimento do direito à propriedade.

Assim, liberalismo e neoliberalismo se diferenciam pela internacionalização do capital e pela ação do capitalista internacional, influenciando os governos nas reformas que estabeleceram o novo Estado mínimo. Então, pela influência fora da hegemonia nacional capitalista que marcou o liberalismo clássico, o poder soberano político é comprometido e os governos são fragilizados.

\section{REFERÊNCIAS}

CHESNAIS, François. A mundialização do capital. São Paulo: Xamã, 1996. 350p.

IANNI, Octávio. A sociedade global. Rio de Janeiro: Civilização brasileira, 1992. 200p.

\section{REFERÊNCIAS CONSULTADAS}

ANTUNES, Ricardo. Adeus ao trabalho?: ensaio sobre as metamorfoses e a centralidade do mundo do trabalho. São Paulo: Cortez, 1997. 155p.

BOBBIO, Norberto. Estado, governo, sociedade: para uma teoria geral da política. Rio de Janeiro: Paz e Terra, 1987. 177p.

DALLARI, Dalmo de Abreu. O futuro do Estado. São Paulo: Moderna, 1980. 184p.

DEUTSCH, Karl Wolfgang. Análise das relações internacionais. Brasília: UNB, 1992. $320 \mathrm{p}$.

FARIA, José Eduardo et al. Direito e globalização econômica: implicações e perspectivas. São Paulo: Malheiros, 1996. 160p.

LEBRUN, Gérard. O que é poder. São Paulo: Brasiliense, 1984. 123p. 